\title{
Beyond flatland: when smart cities make stupid citizens
}

\author{
Michael McGuire*
}

\begin{abstract}
The 'smart city' —insofar as the concept has any definitive purchase-is really what I termed in my (2008) a'hyperspatial' city. That is, its social world is not just connected, but hyperconnected. This means that the risks it generates are not just those of an everyday physical space, or even what was once termed a 'cyberspace', but perils with multidimensional properties - ones which go far beyond mass data-veillance, or the hacking of a home hub by tech-savvy burglars. For as McLuhan once warned, when citizens are multiply interconnected, the second order nervous system which emerges risks generating debilitation as much as facilitation, deformation rather than information and insecurity rather than security. In this paper I address the nature of this risk from two angles. First the way the advent of the smart city concept has also revealed a striking level of unpreparedness for managing everyday life and security within hyperconnected urban space. Given that cities have always been technologies rather than merely technologized, there are profound questions to be asked about why this latest evolution of our most successful tool for enabling mass proximity social organisation has been perceived to be so different from previous transitions. A second angle focuses more directly upon the metaphysics and ecology of the hyperconnected city. Utilising two key determinants of contemporary urban life, the virtualised economy and automated governance I consider whether life within the smart city may so reorder traditional ideas of security and the citizen that both are rendered obsolete.
\end{abstract}

Keywords: Smart city, Stupefaction, Stultification, Hyperconnection, Chindogo, Technological extension, Technological amputation

\section{'All you had you wasted'}

\section{Introduction}

What exactly is 'smart' about a smart city? Does it involve the citizens who make up its population, or is smartness a property of the city itself? And should smartness be read in comparative or purely descriptive terms? That is, should we take the smart city concept to imply that urban environments have become more smart than they used to be, or does the term refer exclusively to the range of information based benefits now available to contemporary city dwellers? These are not trivial definitional questions. The term 'smart city' is one that come with a host of implicit associations, whether these involve supposed benefits like enhanced security and a better quality of life, or simply more informed ways of utilising services. But such assumptions need far more testing-in particular

\footnotetext{
*Correspondence: m.mcguire@surrey.ac.uk
}

University of Surrey, Guildford, UK the assumption that everyone knows what smartness amounts to. In this paper I aim to interrogate some of these questions by relating the development of the smart city to a wider set of reflections about technology and its interfaces with everyday life. Considered through this wider lens, some of the optimistic claims being made by 'smart city' advocates (see for example, Belanche et al. 2016, Neckermann 2017; WEJ 2017; Bibri 2018) become more ambiguous. Just as the process of technologisation has often been argued to be offer us mixed blessings, one where we suffer losses-or amputations as McLuhan put this (McLuhan 1964) - as much as gains, the movement towards more technology dependent cities may come with an under discussed sting in the tale. For, I will argue, as the clamour for smarter cities becomes more strident, we risk damaging the most crucial component of any city-the citizens who constitute it. The problem is this: 
as cities become 'more smart' does this also accelerate a process of what Sennett has called 'stupefaction' (Sennett 2013) - a loss of control over how we use cities? Or is it worse? Is the real outcome stultification-a complementary dynamic where the smarter our cities become the more 'stupid' we all become? If such an observation has any plausibility then profound questions arise-not just about the kind of security smart cities provide but the nature of their impact upon the human condition. For example, though climate responsive thermostats, time-sensitive milking tools and chip-implant operated barn doors may make a herd of cattle 'more secure', it is a reasonable question to ask what type of security this represents? Or indeed, what kinds of animals these then become in acquiring it? A seeming trade-off results, one between a more open ended, dynamic and challenging kind of security and a more controllable, but ultimately stultifying variety.

\section{When cities go smart}

Though the operation of a smart city requires a significant amount of technological complexity, the basic ambition behind them is fairly straightforward. A smart city is meant to permit citizens to make informed choices about their environment in order to make everyday life more efficient, less stressful and just 'better' all round. That is, to offer:

... integrated frameworks, procedures, processes, strategies and policies to foster advancement and innovation in urban systems, namely built environment, infrastructure, administration, governance, and ecosystem and human service provisioning, while continually optimising efficiency gains (Bibri 2018, p 3).

Characterised thus, one might reasonably wonder whether this is really so dissimilar to what the project of urbanisation has always involved, especially as population densities began to increase from the nineteenth century (Hall 2001). For, the development of the cities has been a long (albeit not always smooth or continuous) process of enhancements to security, functionality and efficiency. For example, the advent of hard surfaced, asphalt roads from the 1800s (which of course merely reinvented progress already made in earlier societies) (Lay and Vance 1992); the advent of street lighting in the 1800's (Schivelbusch 1995); the development of urban telephone networks in the 1900 s' (Hugill 1999). All represent ways in which cities have not just developed methods of 'working' more effectively, but-without stretching the point too far-have also become 'smarter.' That is, urbanisation has always progressed when it has been able to provide more informed responses to the social and environmental challenges of mass living.
Of course the contemporary advocate of the smart city will object that this is the 'wrong kind' of smartness. For these earlier examples all lack what is usually identified as the crucial factor in making contemporary urban space 'smart'-ubiquitous access to digital, information technology and its network infrastructures. For it is this which now allows a city to,

\section{Make(s) optimal use of all the interconnected information available today to better understand and control its operations and optimize the use of limited resources (Cosgrove et al. 2011).}

Such technologies are interwoven with urban life in increasingly complex ways but ultimately involve,

The effective integration of physical, digital and human systems in the built environment to deliver sustainable, prosperous and inclusive future for its citizens (BSI 2014).

Thus within a smart city we might typically expect to find features like;

- The wholesale embedding of computerised sensors into the urban fabric-including everything from bike racks and lamp posts to advertising hoardings and traffic lights.

- Centralised digital management of home appliances such as internet fridges and remote-controlled heating systems.

- Instantly accessible real time information about ongoing events/incidents such as traffic hold-ups, air quality or, weather movements,

- Comprehensive forms of e-governance and online access to services.

- Intelligent buildings, able to respond to changes in climate, levels of sunlight and so on.

For others, a more catholic view of the smart city prevails, and a recognition that human capital remains as an important ingredient of the smart city as information technology,

A city [is] smart when investments in human and social capital and traditional (transport) and modern (ICT) communication infrastructure fuel sustainable economic growth and a high quality of life, with a wise management of natural resources, through participatory governance. (Caragliu et al. 2011). 
In general however, the buzz phrases about new urban life tend to come back to the same kind of (technology based) themes: efficiency, optimisation, predictability, convenience and of course enhanced security.

Viewed in these terms, who could disagree that the cities of the 21st will not just be smarter than ever before, but will constitute better places to live, places which further our personal development as much as they do urban life in general?

\section{The essence of a smart city?}

A first criticism of the seeming hegemony of the smart city concept might centre upon confusions around what makes a city smart. The stress upon technology as the primary factor here raises the spectre of technological determinism (Feenberg 2002), and highlights a tendency to overlook the central role of human actors in all this (Winner 1977). For smart cities, as with the information society more generally, this has meant that other key contextual factors have been rather overlooked. Aside from the obvious range of political and ideological influences, new kinds of structural and relational factors are playing an essential role in defining life within these evolving urban/information spaces. In particular the new possibilities of social connection/connectibility are far more significant than the form of any technology which produces them. Thus, by focussing more clearly upon connection and its social implications, we can derive a far more complex picture of what is driving the smart city. We can then reimagine this as a series of multidimensional $n$-place relations with relata that can take many forms- i.e.:

$$
\begin{aligned}
& \text { Individual } \longleftrightarrow \text { Individual } \\
& \text { Individual } \longleftrightarrow \text { Datapoint } \\
& \text { Datapoint } \longleftrightarrow \text { Datapoint } \\
& \text { Individual } \longleftrightarrow \text { Time } \\
& \text { Individual } \longleftrightarrow \text { Interpretation }
\end{aligned}
$$

\section{And so on.}

The multidimensional nature of this connectivity cannot be overemphasized. For its impacts go far beyond epiphenomenal features such as user friendly social media tools, or more comprehensive datasets. Rather, it entails a wholly new form of societal structure. It is not just one where anyone can be connected to anyone, from anywhere, at anytime (though this is significant enough). This expanded relational structure also means that individuals can be connected to any kind of information at any time, from anywhere. I have argued elsewhere (McGuire 2008) that the plurality of such relations-which underpin a state of hyperconnection, was rather overlooked in the rush to associate information technology with a 'cyberspace' where the old rules of human interaction somehow became 'virtualised' (Levy 1997). Instead, it now makes equal, if not more sense to think in terms of hyperspatial rather than cyberspatial urban environments. This is no mere terminological nuance. There are substantial explanatory resources to be gained from exploring analogies between the hyperconnected city and the spatial/'hyperspatial' relation previously discussed only by physicists and geometers (cf Pickover 1999; Mlodinow 2003).

One example of this can be had by briefly reflecting upon Edwin Abbotts classic exploration of the impacts of geometry upon social life-his mathematical parable Flatland (Abbott 1884). The novel provides a simple illustration of the relationships between lower and higher order spaces (hyperspaces) and the new kinds of actions and orientations the latter provides-actions which appear quasi-magical to inhabitants of 'lower order' spaces. For example, Abbott shows how inhabitants of a purely ' 2 dimensional' world (where there is no 'up' or 'down' direction) would view the appearance of a simple 3D object like a sphere as something strange and inexplicable. Since its full dimensions would be invisible to them, all they would witness is a circle (i.e. an intersection of a sphere on the two dimensional plane) which increases and diminishes in size before 'disappearing' (i.e. moving into the invisible up/down dimension). Thus, when the hero of the novel (a Mr A. Square) is lifted 'out' of Flatland into a three dimensional world, he assumes he must have acquired the power of 'omnividience'-an attribute associated with divinity by Flatlanders-because he can see into houses, or locked rooms as a result of being able to view them from above, rather than only from the side.

Such examples suggest how there might be a parallel relationship between pre-digital spaces and the 'hyperconnected' spaces typified by 'data-communication networks'. For, in much the same way, hyperconnection seems to allow us to reshape causality, enabling many previously impossible outcomes to now be realised. Thus, the 'space-time compression' (Harvey 1989) provided by a hyperconnected world means that we can fall in love with someone on one side of the world whilst simultaneously being robbed by someone on its other side. We can create 3D simulations of new buildings before they are built, just as we can conduct immersive walks through city landscapes as they were 500 years ago. We can move rocks around on Mars via a remote interface or we can simply switch on our heating before we get home. By rendering our algorithms as data-rich as possible, it has even become increasingly common to suggest that we can 'predict' and manipulate the future. Such predictive power goes far beyond being able to say whether it might 
rain, or to predict that a train will leave the central station at noon the next day. It has also been suggested that this allows us to anticipate as yet un-actioned behavioursespecially criminal ones-which threaten the enhanced social order smart cities are meant to offer.

Thus, just as the (ostensible) magic of 3D space to Flatlanders is ultimately rooted in material reality, a focus upon hyperspatiality helps remind us that the parallel 'magic' of the smart city also derives from relatively mundane social facts. In the remaining sections of this paper I will explore how our failure to appreciate this has been instrumental in the process of stultification smart cities seem to induce.

\section{Smart cities and stultification}

In his discussion of two typical 'off the peg' smart cities-Masdar (in the United Arab Emirates) and Songdo (in South Korea) Richard Sennett made the following observation:

\section{A large city can be thought of as a complex organ- ism whose innards do not work perfectly in sync, whose parts do not add up to a unified whole. Yet there is something valuable just about these disso- nances. They can create opportunities economically, when someone seizes on a market irregularity, while lack of coherent control enables personal liberty, and disorder might make subjective experience rich and multi-layered-at least novelists from Defoe to Proust hoped so. To take advantage of these possibilities, the big city needs to be learnt. The risk is that new tech- nologies might repress the inductive and deductive processes people use to make sense, for themselves, of the complex conditions in which they live. The smart city would then become a stupefying smart city. (Sennett 2013)}

Sennett concurs with the idea that there is no 'magic' behind what a smart city can offer. Rather, just like many previous urban environments, smart cities are simply complex socio-technic structures. Attempting to manage this complexity by drawing upon technological solutions that are 'too joined up' simply fosters enhanced forms of control. The result is that exploration, uncertainty and the inherent irregularities of more organic urban spaces become stifled. We cease to have to 'work out' how to use and interact with the city and it is at that point where what he calls 'stupefaction' begins. But rather than stupefaction-which implies mere bewilderment or a (temporary) loss of sense, I argue that there may be deeper and longer lasting impacts. The smart city may stultify far more than it stupefies - that is, it may so actively denude and erode our traditional capacities to use urban space that its citizens (literally) become stupid. And whilst stupefaction primarily negates the 'rich and multi-layered' subjective experiences previously enjoyed by the urban flaneur, stultification has wider consequences. For it affects a far more diverse range of individuals who occupy and use urban environments,- whether to conduct their work, bring up families, or simply for leisure. In the following sections I will review some of the ways in which smart cities appear to foster stultification and what this implies for the way humans come to dwell within them.

\section{Types of stultification}

Unnecessary complication, over-engineering and stupidity An oft cited virtue of technology rests upon the mantra of 'ever increasing efficiency' (Marcuse 1982). Such efficiency is perceived as plastic and flexible, enabling us to do everything from working more quickly, calculating more accurately, seeing and hearing more precisely and at greater distances, thinking more rationally, eating more healthily and ageing more slowly. It has even been claimed that improved efficiency allows us extend time itself, creating 'more than $24 \mathrm{~h}$ a day' (Archer 2016). When this kind of received wisdom has been directly questioned the challenge has tended to focus upon deciding which technologies are more efficient, rather than the more fundamental question of whether technology is efficient at all. But is it always a given that a technological solution is the more efficient option, or that it is part of the essence of technology to be 'efficient'? Part of the problem in answering this lies in the subjective character of many judgements of efficiency and how to distinguish between what counts as 'useful' or efficient in one context and what counts as wasteful or inefficient in another. To Bataille for example, the wasteful, or the unproductive remains just as an important feature of industrialised economic and social life as it was in the pre-industrial world (Bataille 1991), albeit less obviously. Whilst premodern societies were comfortable with extravagant forms of waste (such as disposing of an individuals entire wealth within their tomb) we have lost the sense that there is any worth in engaging in (seemingly) unproductive and inefficient activities. In the modern 'restricted economy' we tend to favour 'what works' over the kinds of activities (such as art) that "have no end beyond themselves" (Bataille 1985, p 118).

By reconsidering where the lines between waste and efficiency should be drawn, questions about how efficient we can assume any technology to be come into a clearer focus. Is there always a necessary connection? Can some technologies be inefficient? And if they are, at what point does it become stupid to assume that an inefficient technology is efficient merely because it's a technology? One striking visual interpretation of this conundrum was 


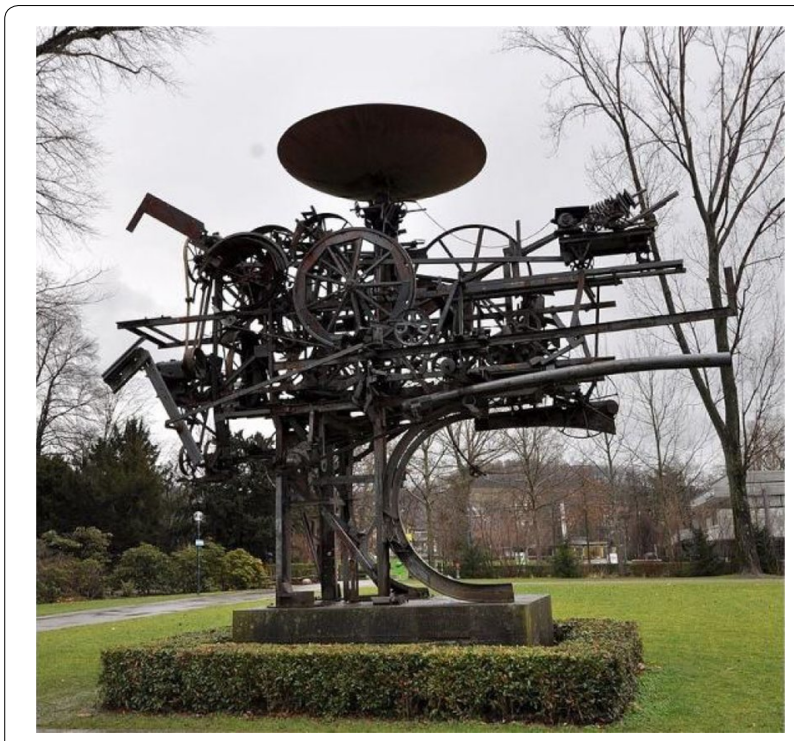

Fig. 1 Tinguelys Eureka machine. Source: https://www.tofugu.com/ japan/chindogu-japanese-inventions/

provided by the French artist Tinguely. Designs like his Eureka machine-the 'good for nothing machine' involve highly engineered assemblages of materials directed to perform useless and inefficient tasks like making cog wheels jam, or engaging in acts of self destruction (Fig. 1).

As the art critic John Canaday once put this-'Tinguely makes fools of machines, whilst the rest of mankind permits machines to make fools of them' (Time 1960) But perhaps the most evocative recent set of examples of inefficient technology have been produced by the Japanese artist Kenji Kawakami. Utilising the concept of 'chindogo' (literally useless machines), Kawakami designed a range of imaginary technological artefacts which perform tasks that are as inefficient as they are ridiculous (Figs. 2, 3, 4).

In one especially prescient example, the idea of a 'selfportrait camera stick' was introduced. At the time, the idea of taking self-portraits with a specially engineered extendible stick seemed about as absurd as tying rags to a crawling baby and calling that a mop. But as so often is the case, reality has ended up reifying the previously surreal, and the 'selfie-stick' is now a (seemingly) fixed part of the urban experience-one that has even generated its own neologism - the 'selfie'. To many, the sight of individuals hauling around mobile phones on sticks in order to generate self-images that demonstrate their presence at famous locations has become an apocryphal signifier of the stupidity of modern life. And even though there are more efficient options available (such as asking someone

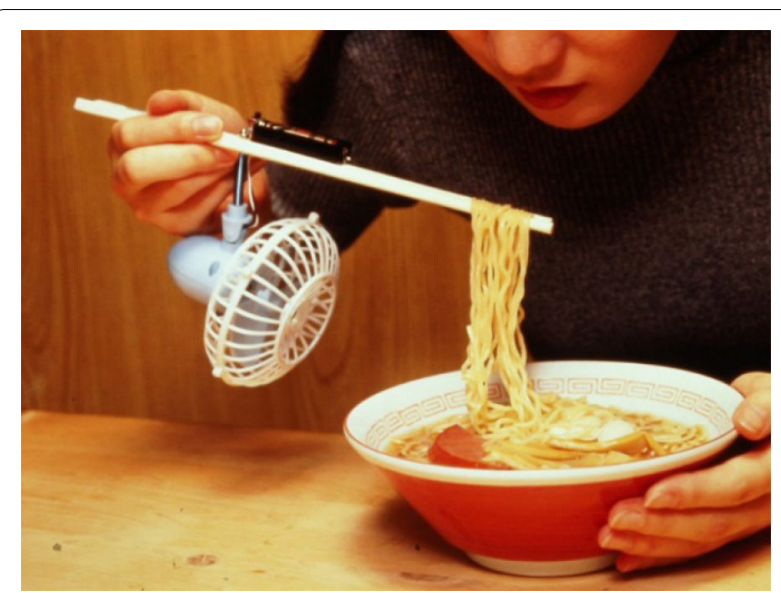

Fig. 2 The noodle cooler. Source: https://www.tofugu.com/japan/ chindogu-japanese-inventions/

to take your photograph) the selfie stick has taken on an air of apparent indispensability in a very short time.

Life in the smart city is replete with similar examples of ever more over-engineered solutions to non-problems like these. Take for example, the 'HAPI-fork' ${ }^{2}$ designed to regulate over-eating by tracking the number of mouthfuls of food eaten during a meal and how many seconds pass between bites. The fork vibrates and lights up if it decides you're eating 'too quickly'. Or what about the SmartMug-which safeguards us against the risks of a burnt tongue by lighting up when a cup of tea of coffee is the 'right temperature; Or for those who find themselves unable to follow a street sign, or read a map, Lechals 'GPS shoes' (with Bluetooth enabled insoles) can guide us safely to our destinations by linking to a preset route on a smart phones and vibrating when it is time to turn left or right (Fig. 5).

Whilst these examples appear to be unlikely fictions they are all real products and mirror far more extensive instances of banal or unnecessary technological 'solutions' to smart city living. It is not hard to see how such solutions risk stultifying rather than extending us. ${ }^{3}$

\section{Innattentional blindness and stupidity}

The tendency to perceive far less of the world than we think we do is significantly exacerbated by life in a smart city where we are constantly bombarded by distractions and desensitised to large parts of our environment. Overfamiliarity and our readiness to edit out informational

\footnotetext{
${ }^{2}$ https://www.hapi.com/product/hapifork.

3 See https://www.linkedin.com/pulse/20140920124414-16774143-10-stupi dest-innovations-the-worst-over-engineered-product-ideas-of-2014 for more examples.
} 


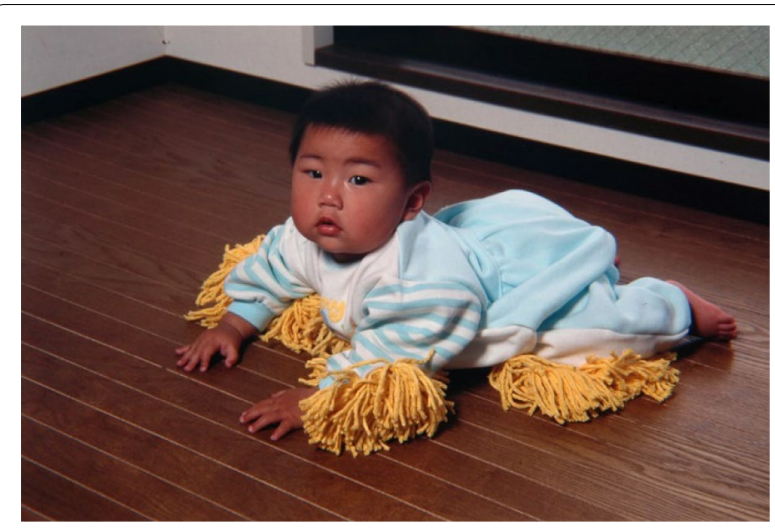

Fig. 3 The baby mop. Source: https://www.tofugu.com/japan/chind ogu-japanese-inventions/

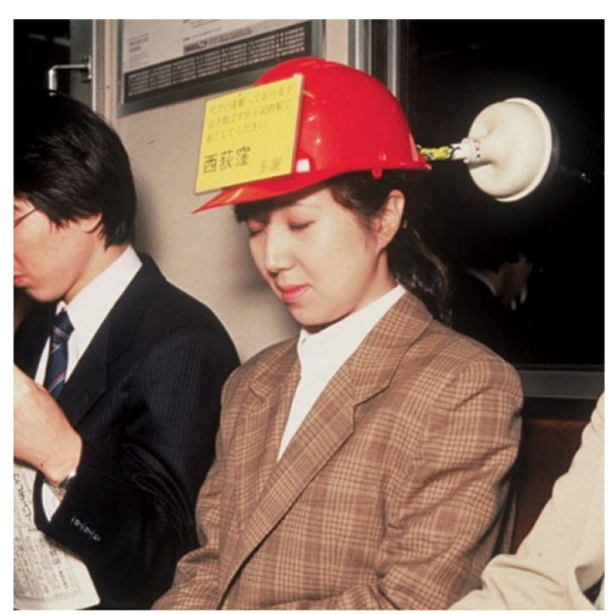

Fig. 4 The subway sleeper. Source: https://www.tofugu.com/japan/ chindogu-japanese-inventions/

'noise' is key to this and anyone who has lived next to a busy road will recognise how easy it becomes after a while to 'tune out' the sounds of vehicles. In this and other ways we have become highly proficient at 'deleting' those parts of the urban sensorium which we wish to ignore. Such tendencies become increasingly significant in a world where technology is embedded into every object and process within our immediate environment. For it is not just that we simply cease to pay attention to the technological origins of any solution or support offered by a smart city but-far more dangerously-we fail to perceive it all. Heidegger once observed that "the more efficiently the tool performs its function, the more it tends to recede from view". (Harman 2002, p 21) and, as Ihde predicted (1993), it is increasingly clear that we live in a world where we no longer properly notice technology-until it ceases to work.
Our capacity to overlook significant objects and events which are right in front us was long ago anticipated by Walter Benjamin in terms of what he called the "casual noticing, rather than attentive observation" (Benjamin 2002, p 120) of urban architectures. The idea that, by opening our eyes we take in everything within our field of vision seems like a natural assumption prima facie, but overlooks factors like over-familiarity or distraction which can cause us to become oblivious to the seemingly obvious. Psychologists have analysed these tendencies in terms of the concept of 'inattentional blindness' (Mack and Rock 1998) and illustrated how this functions by way of various experiments. In one, Mack and Rock asked participants to view a small cross which appeared on a screen and to decide which of the crosses arms was longer than its others. After a number or trials another, unexpected object was introduced in the visual field-such as a brightly coloured rectangle. They found that many participants often failed to see the object, but as soon as their attention was not distracted by the cross they easily registered their appearance. They concluded that, unless our attention is directly stimulated, perception either does not occur, or happens only subconsciously. A more recent demonstration of this effect is the famous 'gorilla experiment' (Chabris and Simons 2010) where observers are invited to observe two basketball teams, one dressed in white and the other in black and asked to count how many times one team passes the ball to other team members. Because of their focus upon the task, up to $50 \%$ of participants fail to notice when someone dressed in a gorilla suit walks across the scene, stops in front of the camera, beats his chest and walks off.

A particularly insidious form of stultification results from inattentional blindness when we are exposed to complex technologies-especially the assemblage which characterises smart cities. One the one hand, having things done for us which we used to do ourselves results in a kind of infantilisation (Bernardini 2014). But it also generates a kind of atrophy within our critical faculties and a 'taken-for-grantedness' of the (ostensibly) seamless embedding of everyday life into technology. Increasingly, our capacity to challenge or even to conceive of alternatives becomes subsumed within a distracted indifference to what the smart city is doing-other than an expectation that it will continue to do it. This, then is a kind of stultification which directly endangers us-partly because we become 'comfortably numb' and lose any sense that things could (or should) be done differently. But, more seriously, our expectations that almost any challenge can be managed by way of a menu of personalised 'solutions' provided 


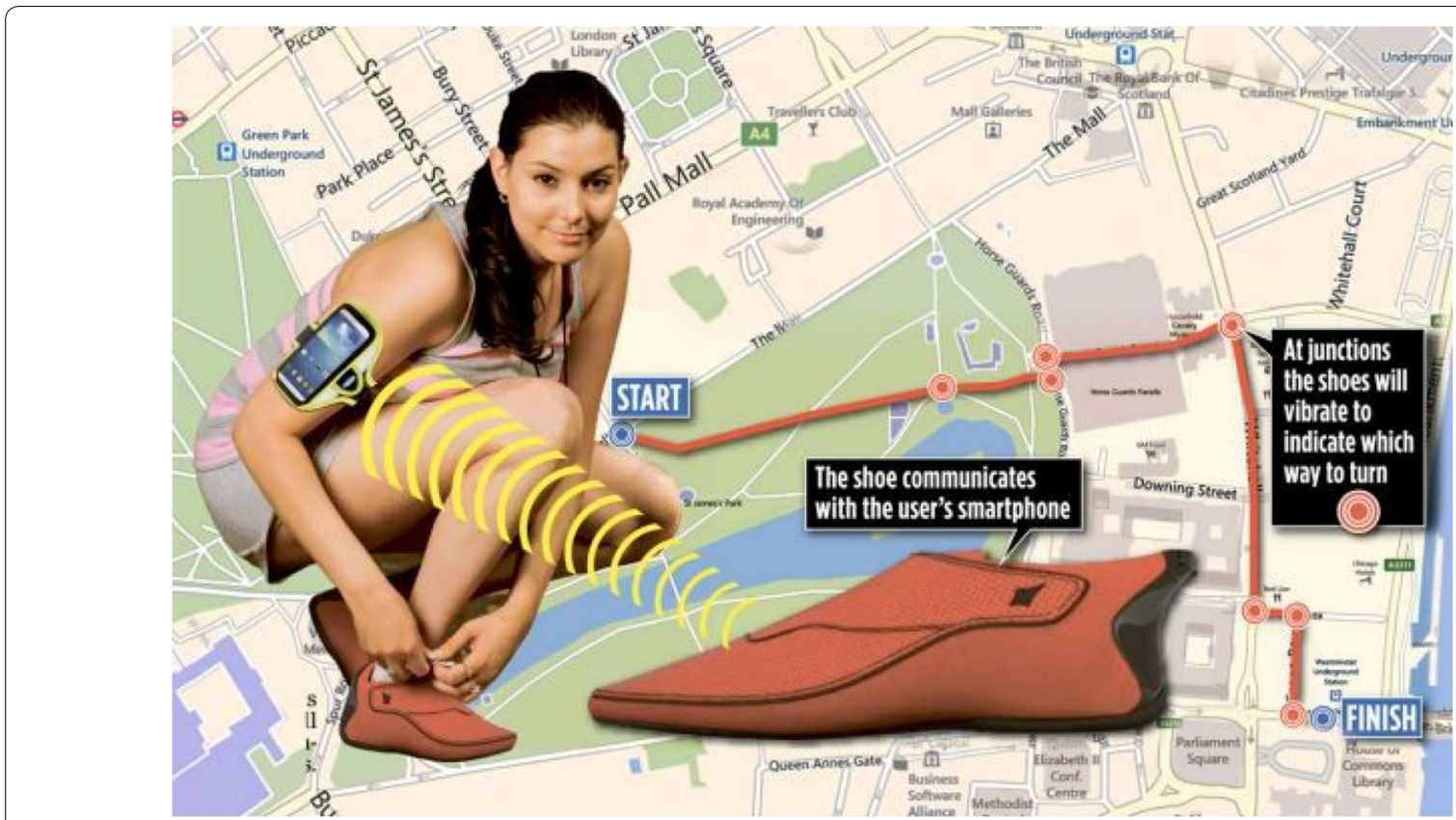

Fig. 5 The 'GPS shoe'

by the smart city, risks damaging our traditional capacity to act when disaster strikes or our devices cease to function.

\section{Gratitude, trust and stupidity}

A third form of stultification induced by the smart city relates to peculiar set of contemporary transactional relations. These involve the provision and exchange of the information technologies so vital to the smart city. No artefact emerges in cultural isolation so it is worth recalling just how comprehensively the slogan 'information is free' permeated early digital cultures (cf. Anderson 2009). This idea is still visible in presumptions about our 'right' to freely access online information in all its forms - whether this involves music downloads, copies of TV shows, software, browsers and so on. Such presumptions have had a significant influence upon the business models of many of the major wealth generators of the information age from Google, to Facebook. An essential feature of what has been dubbed the 'platform capitalist' economy (Srnicek 2017) is the commitment of these platforms to giving away their complex tools and services to users-seemingly for 'free'. No-one 'pays' for a Google Browser, just as there is no subscription for Facebook services and this has encouraged us to think that similar principles apply to any information technology environment. Thus, we increasingly expect (and demand) urban spaces to provide technological services-whether these involve public wi-fi zones, digital displays of information like transport updates, services made available via 'freeto-download' apps, and so on. But this is not public beneficence in the 19th century sense, for the idea that we are getting something for nothing is almost always an illusion. In reality there is always something we must pay back to the modern providers of such public largesse. Most often our paybacks come in the form of the most valuable commodity available within an information society-our data (and lots of it), but on a deeper level something still more personal is also surrendered. For such transactions rest upon their real nature being cleverly concealed, and the impression maintained that the service and support provided comes in the form of a 'gift'. But as Maus once pointed out, the gift economy is never wholly altruistic, or entirely benevolent, for it always involves an obligation of some kind (Maus 2016). On the one hand, there is the initial obligation to provide the gift. On the other there is always an obligation to 'pay back' any gift with another. Viewed in this way the technological largesse of the smart city becomes part of a complex set of social relations which tie us into a vicious cycle of obligation and reciprocal giving, one where all we can provide in return for the original gift is ourselves (cf. Schuilenburg and Peeters 2017)

Gifts also induce gratitude and gratitude as Simmel once observed is a very powerful kind of social tie. Simmel also pointed out that it is an asymmetric tie, for the giving of the gift, in effect, creates the bondage of gratitude-a moral "character indelebilis" $-\mathrm{a}$ tie that 
can never be fully discharged. In this sense, gratitude is a far more powerful social relation than it might at first seem for it may be the only one of our feelings which can be demanded. Ingratitude is simply not an acceptable response to generosity and so we become the unconditional subject of the giver, or at least the giving act.

It is perhaps here where we can most clearly discern how this variety of stultification emerges. It is visible in the way that we fail to notice that the gift-giving act is phoney and leads us into a cycle of gratitude and obligation without anything really having been given for free. It is visible in our compliant willingness to become subjects because we have seem to have been granted gifts by the smart city. But it is perhaps most evident in the way gratitude for the technological 'gifts' provided by a smart city so quickly blurs with trust. What Morozov has called 'technological solutionism' (Morozov 2014) - the faith that where there is a problem, technology will invariably offer the best solution can be directly correlated with this more insidious side effect. For just as the Flatlanders saw magic in simple spatial rearrangements, the quasi'magic' of hyperspatialised technological solutions can be directly related back to the gratitude we feel for having been granted them.

And so we relax, sated and secure in our gratitude. We are content to permit the technological solutions of the smart city to work invisibly, for the field of control which emerges is inconspicuous and so never appears threatening. If anything, it is benevolent, dispensing further gifts such as security, efficiency and comfort, all wrapped up within alluring user interfaces. But of course invisible solutions also mean solutions with no accountability. And so we grant authority to remote and indecipherable forms of power and control-an authority we would never have granted had it been driven by overtly human agents. The result, is an increasingly seamless field of relational control which uses hyperspatial technologies to direct itself from everywhere, to everyone, all of the time. Deleuze was well aware of the important effects of this shift upon the nature of control. For it represents a shift away from earlier, disciplinary power which operates via enclosure (such as that seen in factories, schools or prisons) towards a more universal, more modulated form. That is, towards a continuous, unbounded network of control where access is delimited by our data and signified by passwords/code (licit or illicit) or the database itself (Deleuze 1992). Access details are, in effect, the gifts we reciprocate-the obligation to which we are bound in virtue of the original gift we received. But since our awareness of how we fulfil our obligation is limited, we always seem to be in debt, always in hoc to further obligations. Thus, as we marvel at our intelligent transport networks, smart cards and driverless vehicles which can take us anywhere-we forget that they are recording our every movement. As we delight in home hubs which talk to us, time control our lighting, remind us that it is our wedding anniversary or allow to see who is ringing our doorbells when we are away, we are willing to overlook the detailed information about our lives which is passed on as a result. And as we come to depend upon smart technologies to send us updates about the weather, available parking spaces and even crime alerts, we ignore the resulting micro-portrait of our tastes and preferences which also emerges. Our sense of benefit, or security is thus far more a product of stultification than genuine material reward, for it rests upon our failure to notice that there is no debt, and that we have given away far more than any gift could obligate.

\section{Reductions of uncertainty and a false sense of security}

Hobbes, Bentham and Mill and most of the classical writers on security were in agreement that the promise of security has been one of the most appealing motivations for a civil society. But, as just suggested, the kind of security offered by a smart city involves a far less transparent contract between citizens and governance than these early thinkers originally proposed. It also depends upon a highly questionable premise-the idea that its technologies enhance security by 'reducing uncertainty'. Many of our current ideas about security centre upon the belief that we have tools which enable us to predict (and thereby manage) the future. The promise of predictive technologies and predictive analysis, which is meant to tell us, "what happened, how it might unravel, and what is the general possibility of events happening in the future" (van Hooijdonk 2017) are cornerstone ingredients of the smart city's offer of greater security. For example, the use of predictive policing software like 'Predpol' which tells us where to arrest burglars offers the promise of reducing social disorder (Moses and Chan 2016); Forecasting tools which use satellite and similar data to predict extreme weather events like tropical storms, or natural disasters like landslides offer the promise of greater safety; 'Smart energy' software which predicts peak flows and troughs in energy usage offers the promise of more economical power; Integrated transportation tools which anticipate likely bottlenecks offer the promise of more effective traffic and transport solutions. When coupled with the techniques of 'predictive maintenance' (Levitt 2003) which promises to use the monitoring of key parameters to anticipate when systems need to be taken offline or to be fixed, we seem to arrive at a state of perpetual safety and total security where nothing threatens, where discomforts vanish and where nothing is ever at risk of malfunctioning again. And at this point a quasi-magical, almost divine perception of security re-emerges, for 
when applied to our own bodies predictive maintenance has been argued to offer the prospect of extending life itself (Zell 2017)!

But the assumption that, by reducing uncertainty, we so exhaustively rearticulate our relationship with time that the future ceases to be an unknown, is as flawed now as it was when Roman priests assumed animal entrails would foretell what the future might bring. For whilst we have been very successful at utilising scientific understanding to make certain predictions about the natural worldsuch as the date of equinoxes or how two elements will react when brought together, that same understanding also tells us that there are also strict limitations imposed by nature upon our capacities to predict the future. The butterfly effects within complex, non-linear systems, the NP limits of computable functions or uncertainties at the quantum level itself are amongst multiple kinds of phenomena which remind us that unpredictability is not just an epistemic fact but something which operates at a far deeper, ontological level in the world. And as Sennett and others have argued (cf Floridi 2015) this may be something to be embraced, rather than evaded, Thus, in a world irreducibly shaped by indeterminacy and the random effects of human subjectivity, to assume that technology will guarantee us secure knowledge of the future is not just folly but stupidity of the highest order.

\section{Amputation and stupidity}

A final way in which the smart city is as likely to stultify as it is to enlighten operates as a kind of background factor within all of problems identified above. It derives from a recurring paradox about technology, the fact that it always appears likely to have as many negative impacts as it does benefits (Postman, 1993; Feenberg 2010). Long before the first Luddite broke the machines which had permanently made their skills redundant, classical theorists like Plato and Aristotle were cautioning that purely technological driven approaches "represented an aspect of brute force and implied a want of moderation" (Ellul 1964, pp 28-29)

One of the starkest, and most evocative accounts of this paradox of technological gain and loss was theorised by McLuhan in terms of his distinction between technological extension and technological amputation. McLuhan recognised that, "All technologies are extensions of our physical and nervous systems to increase power and speed" (McLuhan 1964, p 90), and provided numerous instances of this. For example, the wheel extends our feet just as the phone extends our voice. But with every additional capacity we gain through technological extension comes a loss-an 'amputation. Thus wheels may allow us to travel faster and more widely-but we see and experience far less along the journey than if we had walked.
Similarly, the telephone, and more recently social media, have allowed us to talk more widely and with more people, but with none of the verbal cues and communication 'depths' of F2F conversation, or the written word. In this way something fundamental and instinctive about human interaction has arguably lost forever (Turkle 2012, Chan 2014).

McLuhan suggested that this process of extension/ amputation, has been decisively shifted by the advent of 'electric technologies' for these involve impacts upon our 'inner' as well as our outward faculties. Since these now extend our central nervous system as much as they do our brains, the result is that,

... we approach the final phase of the extension of man-the technological simulation of consciousness, when the creative process of knowing will be collectively and corporately extended to the whole of human society, much as we have already extended our senses and nerves by the various media $(1964,4)$

Amongst the sweeping costs to this shift are a range of amputations which directly limit our faculties and our consciousness. For example, whilst the smart city and modern analytic tools act together to assemble our consciousnesses into an interconnected nervous system which permits us to live 'more connected', more convenient lives, they also promote increasing stress and nervous anxieties. They involve the loss of key abilities and faculties such as navigation and spatial awareness; our capacity to engage in face to face contact and intimacy; the capacity to wander and experience urban space randomly (like the flaneur) - and so on. Worse still, the 'global village' that results from global communication networks produces a world where oral communications (like text, social media posts etc.) gain a new kind of precedence and rumour and gossip become increasingly foregrounded over truth. Our very capacity to distinguish fact from fiction thereby becomes lost in a slew of relative perceptions and 'alternative' facts. The stupidities around producing or believing in fake news represent one of the more obvious consequences of these kinds of amputation. But McLuhans conclusions about where this might lead indicate a worse kind of stupidity. For in the hyperconnected world and the smart city, McLuhan sees;

\section{"... a development that suggests a desperate and sui- cidal auto-amputation" (1964, p 43)}

That is, a process whereby human beings now voluntarily set aside their own abilities in place of technological substitutes. The passivity of human responses in the face of hyperconnected technical domination results in a kind 
of surrender to machinic logic and technological rationality likely to subordinate humanity more effectively than any human dictator has ever done. And if accepting that is not stultification it is hard to know what is.

\section{Conclusion}

The rewards of living in a smart city may turn out to match the hype, but this outcome is far from clear at present. The argument outlined above has identified a number of reasons for being sceptical about the promise of the smart city to offer enhanced security and well-being. For Sennett, the problem lies in the way smart cities zone, bound and constrain the open, non-linear aspects of traditional urban spaces which encourage informality, spontaneous interaction and ideas. In the smart city there are no grey zones where the rules are uncertain, no interstitial places where unfiltered, unregulated, 'ground upwards' interaction can easily occur. And by removing our need to 'learn' how to orient ourselves within urban spaces, smart cities thereby 'stupefy' us. I have suggested that there may be good reasons for thinking that smart cities do something worse-a process of 'stultification' rather than stupefaction. For within the comforting embrace of the smart city we become less aware of substantive threats and less able to respond to them as they arise. We become immured within over engineered, over complex environments where technological solutions blind us to other varieties. And within such spaces technology becomes such a norm that we become effectively blind to its actions and to its impacts. In effect, we enter into a state of denial about the fundamental uncertainties which make up the world and substitute blind trust in technological solutionism for informed, objective evaluation of what is gained and what is lost when algorithms are permitted to run societies. And as recipients of technological gifts we cease understand how easily we have become locked into a cycle of obligation and gratitude which is often more akin to addiction than informed consent.

In doing all this, the smart city risks erasing the very essence of what cities are meant to be, for they make us lose sight of the very thing which once defined them-its citizens. And since a city with no citizens is scarcely worthy of the name, this seems like a pretty stupid kind of an outcome for any city.

\section{Authors' contributions}

The author read and approved the final manuscript.

\section{Authors' information}

Michael McGuire is Senior Lecturer in Criminology at the University of Surrey, UK. He has developed an international profile in the study of cybercrime, technology and the justice system and has published widely in these areas. His first book Hypercrime: The New Geometry of Harm (Glasshouse, 2008), was the first to define cybercrime in terms of the concept of hyperconnectedness and was awarded the 2008 British Society of Criminology runners up Book
Prize. His most recent publications, Technology, Crime \& Justice: The Question Concerning Technomia and the Handbook of Technology, Crime and Justice (Routledge, 2012 and 2016) have provided comprehensive overviews of the implication of technology for the justice system. These complement a range of applied studies of cybercrime, including Cybercrime, A Review of the Evidence for the UK Home Office (2014) and Into the Web of Profit (2017), one of the comprehensive investigations into the structure of the cybercrime economy. $\mathrm{He}$ is currently one of the lead investigators for the $\$ 1.5 \mathrm{~m}$ ACCEPT project (Addressing Cybersecurity and Cybercrime via a co-Evolutionary aPproach to reducing human-relaTed risks) funded by the UK Engineering and Physical Science council. The project aims to develop a co-evolution based methodology for modelling human factors in cybersecurity.

\section{Competing interests}

The author declares no competing interests.

\section{Publisher's Note}

Springer Nature remains neutral with regard to jurisdictional claims in published maps and institutional affiliations.

Received: 1 March 2018 Accepted: 21 September 2018

Published online: 01 December 2018

\section{References}

Abbott EA (1984) Flatland: a romance in many dimensions. Dover, New York Anderson C (2009) Free: the future of a radical price. Hatchette Books, New York

Archer S (2016) Tech has made our lives so efficient it's like having more than 24 hours in a day Business Insider. 8/7/2016

Bataille G (1985) Visions of excess. University of Minnesota Press, Minneapolis

Bataille G (1991) The accursed share: Consumption, vol 1. Zone Books, New York

Belanche D, Casalo L, Orús C (2016) City attachment and use of urban services: benefits for smart cities. Cities 50:75-81

Benjamin W (2002) Walter Benjamin, selected writings, vol 3. Belnap Press, Harvard, pp 1935-1938

Bernardini J (2014) The Infantilization of the postmodern adult and the figure of Kidult. Postmod Open 5(2):39-55

Bibri S (2018) Smart sustainable cities of the future. Springer International, Switzerland

BSI (2014) Smart cities framework — guide to establishing strategies for smart cities and communities. PAS 181:2014

Caragliu A Del, Bo C, Nijkamp P (2011) 2011 "Smart Cities in Europe". J Urban Technol 18(2):65-82. https://doi.org/10.1080/10630732.2011.601117

Chabris C, Simons D (2010) The invisible gorilla and other ways our intuitions deceive us. Crown, New York

Chan TH (2014) Facebook and its effects on users empathic social skills and life satisfaction: a double edged sword effect. Cyber Psychol Behav Soc Netw 17(5):276-280

Cosgrove M (2011) Smart Cities series: introducing the IBM city operations and management solutions. IBM, Armonk

Deleuze G (1992) Postscript on the societies of control. 59, pp 3-7

Ellul J (1964) The technological society. Vintage Books, New York

Feenberg A (2002) Transforming technology. Oxford University Press, Oxford

Feenberg A (2010) Ten Paradoxes about technology. Techne 14:1

Floridi L (2015) The politics of uncertainty. Philosophy \& Technology 28(1):1-4

Hall P (2001) Cities in civilisation. Fromm International, Mt Prospect

Harman G (2002) Tool-being: Heidegger and the metaphysics of objects. Open Court, Chicago

Hugill P (1999) Global communications Since 1844: geopolitics and technology. JHU Press, Baltimore

Lay MG, Vance J (1992) Ways of the world: a history of the world's roads and of the vehicles that used them. Rutgers University Press, New Jersey

Levitt J (2003) Complete guide to preventive and predictive maintenance. Industrial Press Inc, New York

Levy P (1997) Becoming virtual: reality in the digital age, trans. Bononno R, New York: Plenum Trade 
Mack A, Rock I (1998) Inattentional Blindness. MIT Press, Cambridge Marcuse H (1982) Some Social Implications of Modern Technology. In: Arato A, Gebhardt E (eds) The essential Frankfurt school reader. Continuum, New York, pp 138-162

Maus M. (2016), The gift (Expanded Edition) trans. Guyer, J. Hau Books

McGuire MR (2008) Hypercrime: the new geometry of harm. Glasshouse, London

McLuhan M (1964) Understanding media: the extensions of man. McGraw-Hill, New York

Mlodinow L (2003) Euclid's window: the story of geometry from parallel lines to hyperspace. Penguin, London

Morozov E (2014) To save everything, click here: the folly of technological solutionism. Perseus Books, Philadelphia

Moses L, Chan J (2016) Algorithmic prediction in policing: assumptions, evaluation, and accountability. Policing and Society 28(7):806-822

Neckermann L (2017) Smart cities, smart mobility: transforming the way we live and work. Troubadour, Leicester

Pickover C (1999) Surfing through hyperspace: understanding higher universes in six easy lessons. Oxford University Press, Oxford

Postman Neil (1993) Technopoly: the surrender of culture to technology. Vintage Books, New York
Schivelbusch W (1995) Disenchanted night: the industrialization of light in the nineteenth century. University of California Press, Berkeley

Schuilenburg M, Peeters R (2017) Gift politics: exposure and surveillance in the anthropocene. Crime Law Soc Change 68(5):563-578

Sennett R (2013) I'The stupefying smart city' in The Electric City. LSE Cities, London

Srnicek N (2017) Platform capitalism. Wiley, Hoboken

Time (1960) Homage to New York? Time Magazine, 28/03/1960

Turkle S (2012) Alone together: why we expect more from technology and less from each other. Basic Books, New York

van Hooijdonk R (2017) The Future of Smart Cities and Government', Blog post. https://www.richardvanhooijdonk.com/en/future-of-smart-cities-gover nment/

WEJ (2017) The big benefits of smart cities. Wall Str J 23/10/2017

Winner L (1977) Autonomous technology: technics-out-of-control as a theme in political thought. MIT Press, Cambridge

Zell W (2017) Predictive maintenance can bolster loT for smart cities. Meeting of the minds. http://meetingoftheminds.org/predictive-maintenanc e-will-power-iot-smart-cities-24193. Accessed 18 Dec 2017

\section{Submit your manuscript to a SpringerOpen ${ }^{\circ}$ journal and benefit from:}

- Convenient online submission

- Rigorous peer review

- Open access: articles freely available online

- High visibility within the field

Retaining the copyright to your article

Submit your next manuscript at $\boldsymbol{\nabla}$ springeropen.com 